\title{
Environmental impacts of rapid urbanization in China: a showcase of recent research developments
}

\author{
Yong-Guan Zhu
}

Received: 25 April 2012 / Accepted: 27 April 2012

(C) Springer-Verlag 2012

Urbanization is taking an unprecedented rate in China, and it is projected that some 350 million people will be added to the country's urban population by 2025, and 1 billion people will live in Chinese cities by 2030 (Zhu et al. 2011). For the first time in history, China will have over $50 \%$ of its 1.3 billion population living in cities this year. This is remarkable for China, an ancient and more agriculturebased civilization. In many ways, urbanization will improve the quality of sanitary conditions, better health care systems, the efficiency of public transport, and will provide the population with more access to modern civilization. However, it is also clear that urbanization will, in the same time, bring many negative impacts on the environment and human health, as recently highlighted by Zhu et al. (2011). To overcome the negative environmental impacts of rapid urbanization in China is becoming one of the major themes of environmental studies in China.

Urban ecosystem is human-dominated, and the changes in environmental quality and the health of urban ecosystems are largely driven and determined by concentrated human consumption of energy and natural resources. In this special issue, we publish 11 papers to illustrate some of the recent endeavors in investigating the status of urban environmental quality and the impacts of urbanization on environmental

Responsible editor: Philippe Garrigues

Y.-G. Zhu $(\bowtie)$

Key Laboratory of Urban Environment and Health, Institute of Urban Environment, Chinese Academy of Sciences, Xiamen 361021, China

e-mail: ygzhu@rcees.ac.cn changes, as well as technologies to mitigate the negative impacts of urbanization. Two review papers are included in this issue, one by Guo-Ping Sheng provides an overview on wastewater discharge and urbanization in China, and the other one by Chen et al. provides Chinese perspectives of sewage sludge utilization. Four papers examined the current status of environmental quality, such as the occurrence of micropollutants (perfluoroalkyl and estrogenic compounds), sediment quality in urban river systems, particulate matter in urban air, etc. The paper by Jun Yang addresses the issue of aquatic ecosystem health by looking at algal community and trophic state. One paper (by Xinhu Li) looks at the spatial features of the relationship between human health and urbanization. There are also two papers which report some new technological developments that help lessen these environmental problems.

In recent years, publications related to "urbanization and China" have increased dramatically, from 21 in 2000 to 337 in 2010 (Web of Science, accessed on 11 March 2012). Therefore, by no means will this special issue provide a full picture of urban environmental studies in China; rather, it serves as a window to showcase the recent developments in urban environmental studies.

\section{Reference}

Zhu Y-G, Ioannidis JPA, Li H, Jones KC, Martin FL (2011) Understanding and harnessing the health effects of rapid urbanization in China. Environ Sci Technol 45:5099-5104 